\title{
Procurement Strategies Using Portfolio Approach Based on Options and Spot Markets Procurement
}

\author{
Wang Heng ${ }^{1,2} \& \mathrm{Xu} \mathrm{Qi}^{1}$ \\ ${ }^{1}$ School of Glorious Sun of Business and Management, Donghua University, Shanghai, China \\ ${ }^{2}$ School of Information Engineering, Ningxia University, Yinchuan Ningxia, China \\ Correspondence: XU Qi, School of Glorious Sun of Business and Management, Donghua University, Shanghai, \\ China.E-mail: xuqi@dhu.edu.cn
}

Received: June 26, 2017

doi:10.5539/ijbm.v12n10p212
Accepted: August 20, 2017 Online Published: September 17, 2017

URL: https://doi.org/10.5539/ijbm.v12n10p212

\begin{abstract}
The paper explored the conditions for retailers to implement option contract and the strategies to make joint purchase in spot market. Under the condition of uncertain market demands, a joint purchase model integrating batch ordering, option contract and spot market has been developed. Considering price fluctuation, the conditions for implementing option contract-based ordering have been studied; the impacts of price fluctuation and option execution price on retailers optimal ordering of joint purchase have been analyzed as well. The result shows that if a retailer adopts a joint purchase strategy, certain constraints need to be met. Otherwise, it is more conductive for the retailer to maximize revenues by adopting a single purchase order. When the spot market is involved, the total order quantity and the order quantity of option contract are negatively correlated with the option execution price and are positively correlated with the spot price fluctuation; and, the order quantity of bulk order contract is positively correlated with the option execution price and is negatively correlated with the spot price fluctuation.
\end{abstract}

Keywords: Supply chain, Options contract, Spot markets, Procurement strategies

\section{Introduction}

The option contract brings about a risk sharing mechanism for purchase management of supply chain. The supplier serves as the issuer of the options contract. The retailer pays the option reservation price to the supplier, which is deemed as the deposit for the option contract. In the contract they agree that, the retailer will be entitled to purchase commodities from the supplier at the option reservation price and to the extent not exceeding the quantity as agreed in the contract at a certain time in the future. The retailer, by entry into an option contract with the supplier, transfers the purchase risk of goods to the supplier so as to cope with stochastic market demands in the future. The supplier obtains the reservation price of the option contract as a compensation for sharing the order risk of the retailer; and by doing so the retailer is urged to purchase more while the retailers order quantity is more accurately grasped. It therefore reaches a win-win result for both parties to the option contract. The involvement of the spot market allows more available channels for the retailer. When the spot market price is lower than the option execution price in the future, the retailer may give up exercising the option and replenish in the spot market instead, which maximizes its revenues.

Black and Scholes (1973) studied the realization of supply chain collaboration by means of flexible option contracts and established a basic option supply model including option trading. Barnes-Schuster et al. (2002) analyzed issues regarding the supply chain flexibility and coordination based on option contracts. Seifert et al. (2004) researched order strategies of the retailer in relation to market demands and the spot price when the spot market was involved and discussed the impacts on the purchase model imposed by the spot market. Martłnez-de-Albniz and Simchi-Levi (2005) studied the joint purchase strategy composed of bulk order contracts and option contracts under multi-cycle conditions. Fu et al. (2010) discussed the single-cycle combined order strategy and portfolio effects based on option contract under random spot prices. Inderfurth and Kelle (2011) revealed in their study of joint purchase strategies under the condition of reserve capacity and purchase in he spot market and analyzed the impacts on supply chain coordination imposed by factors such as market price fluctuation, cost and inventory strategies. Xing et al. (2012) discussed purchase strategies and supply chain coordination for purchasing from conventional channels and e-commerce spot when the B2B spot market was 
involved. Hong and Lee (2013) researched order risks when the spot market was involved and put forward the realization of selecting suppliers and distributing orders by a decision support model. Liu et al. (2013) studied the application strategy of one-way and two-way options in different scenarios of container shipping service chain. Zhao et al. (2013) analyzed the coordination of two-way options to supply chain, focusing on the feedback impact on retailers initial order strategies imposed by the capped option. Merzifonluoglu (2015) discussed mixed order strategies of retailers who purchase by integrating long-term contracts, option contracts and spot purchase under varied risk attitudes when the market demand, spot price and spot market were involved in different ways. Arani et al. (2016) provided a new revenue sharing model regarding the issue of option contract-based supply chain coordination and discussed the supply chain coordination where retailers and manufacturers were considered supply chain leaders and the manufacturers output issues at Nash Equilibrium.

This paper is based on the perspective of retailers. It takes the bulk purchase contract as the main way of purchase, the option contract and the spot market as the ways to expand purchase for coping with the uncertainty of market demands in the future and studies the mixed purchase strategy. This paper focuses on two issues: 1) the conditions and strategies for selecting the correct purchase channel after the forecasting information is made by the retailer; and 2) the impacts on the optimal purchase quantity of the retailer imposed by the key factors such as the fluctuation of the spot market price and the option execution price.

\section{Model Description}

We consider a single-period supply chain consisting of a retailer and a supplier with stochastic market demand. For the coming season of sale, the supplier release a bulk order contract and an option contract, knowing the unit wholesale price $w$ of bulk order contract, unit reservation price $c_{o}$ and unit execution price $c_{e}$ of the option contract. Retailer buys options from the supplier, and submits the quantity $Q$ to order through bulk order contract and quantity $M$ to order through option contract by making reasonable analysis which based on predicted price volatility characteristic information connecting with the spot market to record their history of procurements. The orders are used to meet future uncertain market demands. The retailer is risk neutral in the procurement process. The retailer can choose to procure from supplier by signing certain option contracts, or tap into the spot market and purchase the products at a random spot price $c_{s}$. Let $\mathrm{D}$ denote the random demand, and let $f(x)$ and $F(x)$ denote the pdf and cdf of the random demand D. $\bar{F}(x)=1-F(x)$. The demand and spot price are independent, and let $g(s)$ and $G(s)$ denote the pdf and cdf of random spot price $c_{s}$, which follows a normal distribution $c_{s} \square\left(\mu_{s}, \sigma_{s}^{2}\right)$.

When a sales season coming, at the same time of performing the bulk order contract, the retailer also make decisions on replenishment channels and quantity according to market demands and the comparison between the actual price of the spot market and the execution price of option contract. The selling price of unit is $p_{r}$, and the unit salvage price of the unsold goods is $v_{r}$ at the end of the selling season.

Assume that the parameters have the following relationship: $v_{r} \square w, w<c_{e}$. The first item ensures that it is a possible choice for the retailer to perform the bulk order contract; and the second item enables the possible performance of the option contract.

\section{Joint Purchase Model}

The order quantities based on bulk order contract and option contract that shall be met in the order phase can be informed by the action strategies the retailer has taken in the sales season. When a sales season comes, the retailer determine the channels and quantity to replenish by comparing the order quantity with the actual market demand and the spot market price with the futures execution price for maximization of its own revenues.

(1) For $0 \leqslant D \leqslant Q$, a certain quantity of goods based on bulk order is unsold and unsold goods end up in the 
form of salvage value. The retailer no longer adds any form of replenishment. The retailer's revenue $\Pi_{R}$ can be written as follows:

$$
\Pi_{R}(Q, M)=p_{r} x-w Q-c_{o} M+v_{r}(Q-x)
$$

(2) For $Q<x \leqslant Q+M$, the retailer needs to choose the lower cost of the stock as the source of the replenishment by comparing the spot price of the commodity and the price of the option. The retailer's revenue $\Pi_{R}$ can be written as follows:

$$
\Pi_{R}(Q, M)= \begin{cases}p_{r} x-w Q-c_{o} M-c_{s}(x-Q) & c_{s}<c_{e} \\ p_{r} x-w Q-c_{o} M-c_{e}(x-Q) & c_{s} \geqslant c_{e}\end{cases}
$$

(3) For $x>Q+M$, aimed at maximization of its own revenues, when spot price is less than execution price, the retailer replenish from the spot market; when spot price is greater than execution price, the retailer first perform all options, and then replenish from the spot market . The retailer's revenue $\Pi_{R}$ can be written as follows:

$$
\Pi_{R}(Q, M)= \begin{cases}p_{r} x-w Q-c_{o} M-c_{s}(x-Q) & c_{s}<c_{e} \\ p_{r} x-w Q-c_{o} M-c_{e} M-c_{s}(x-Q-M) & c_{s} \geqslant c_{e}\end{cases}
$$

According to the procurement strategies described above, the retailer's revenue $E\left(\Pi_{R}\right)$ can be written as follows:

$$
E\left(\Pi_{R}\right)= \begin{cases}p_{r} E(f(x))-w Q-c_{o} M+v_{r} \int_{0}^{Q}(Q-x) f(x) d x-c_{s} \int_{Q}^{+\infty}(x-Q) f(x) d x & c_{s} \leqslant c_{e} \\ p_{r} E(f(x))-w Q-c_{o} M+v_{r} \int_{0}^{Q}(Q-x) f(x) d x-c_{e} \int_{Q}^{Q++M}(x-Q) f(x) d x & c_{s}>c_{e} \\ -c_{e} M \int_{Q+M}^{+\infty} f(x) d x-c_{s} \int_{Q+M}^{+\infty}(x-Q-M) f(x) d x & \end{cases}
$$

Eq. (4) can be re-written as the conditional probability formula of the price $c_{s}$ at the spot market and the price $c_{e}$ on the options execution, as follows:

$$
E_{C_{s}}\left(E\left(\Pi_{R}\right)\right)=E_{C_{s}}\left(E\left(\Pi_{R} \mid c_{s} \leqslant c_{e}\right)\right)+E_{C_{s}}\left(E\left(\Pi_{R} \mid c_{s}>c_{e}\right)\right)
$$

According to eq. (4) and eq. (5), the joint purchasing strategy, which is composed of bulk order contract, option contract and spot market, can be expressed by the following:

$$
\begin{gathered}
E_{C_{s}}\left(E\left(\Pi_{R}\right)\right)=p_{r} E(D)-w Q-c_{o} M+v_{r} \int_{0}^{Q}(Q-x) f(x) d x \\
-\int_{0}^{c_{c}} s g(s) d s \int_{Q}^{+\infty}(x-Q) f(x) d x-c_{e} \int_{c_{e}}^{+\infty} g(s) d s \int_{Q}^{Q+M}(x-Q) f(x) d x \\
-c_{e} M \int_{c_{e}}^{+\infty} g(s) d s \int_{Q+M}^{+\infty} f(x) d x-\int_{c_{e}}^{+\infty} s g(s) d s \int_{Q+M}^{+\infty}(x-Q-M) f(x) d x
\end{gathered}
$$

\section{Model Solving and Analysis}

Let $A=\int_{0}^{c_{c}} s g(s) d s$ denote an estimate of the average price in spot market based on historical option execution price, and $B=\int_{c_{c}}^{+\infty} g(s) d s$ denote the probability that the spot price is greater than the option execution price $c_{e} . I=\int_{0}^{c_{e}}\left(c_{e}-s\right) g(s) d s$ denote the valuation that spot price is less than the option execution price $c_{e}$.

Theorem 1 For joint purchase model integrating the bulk order contract, the option contract and the spot market, 
if the condition for $c_{e}-\mu_{s}+\frac{c_{o}\left(\mu_{s}-v_{r}\right)}{w-v_{r}}<I<c_{e}-v_{r}$ is met, then the unique optimal $Q^{*}$ and $M^{*}$ is determined respectively by the following:

$$
\begin{array}{r}
Q^{*}=F^{-1}\left(\frac{w-c_{o}-c_{e}+I}{v_{r}-c_{e}+I}\right) \\
M^{*}=F^{-1}\left(\frac{\mu_{s}-c_{e}-c_{o}+I}{\mu_{s}-c_{e}+I}\right)-Q^{*}
\end{array}
$$

Proof. See Appendix A.

Under given conditions, Theorem 1 show that The retailer is risk neutral in the procurement process. In fact, in order to get $Q^{*}$ and $M^{*}$, the boundary conditions are found from considering $F\left(Q^{*}\right)=0$ and $F\left(Q^{*}+M^{*}\right)>F\left(Q^{*}\right)$.

The procurement strategies of retailer can be written as follows:

$$
\begin{gathered}
\text { If } w \geqslant c_{e}+c_{o}-I, Q^{*}=0, \bar{F}\left(M^{*}\right)=\frac{c_{o}}{\mu_{s}-c_{e}+I} ; \\
\text { if } c_{e}+c_{o}-I>w \geqslant \frac{c_{o}\left(\mu_{s}-v_{s}\right)}{\left(\mu_{s}-c_{e}+I\right)}+v_{r}, \bar{F}\left(Q^{*}\right)=\frac{v_{r}+c_{o}-w}{v_{r}-c_{e}+I}, \\
\bar{F}\left(Q^{*}+M^{*}\right)=\frac{c_{o}}{\mu_{s}-c_{e}+I} ; \\
\text { if } \frac{c_{o}\left(\mu_{s}-v_{s}\right)}{\left(\mu_{s}-c_{e}+I\right)}+v_{r}>w, \bar{F}\left(Q^{*}\right)=\frac{c_{o}}{\left(\mu_{s}-c_{e}+I\right)\left(v_{r}-c_{e}+I\right)}, M^{*}=0 .
\end{gathered}
$$

In the case of spot market involvement, when the option price issued by the supplier meets $w \geqslant c_{e}+c_{o}-I$, the retailer's cost of a mixed order strategy will inevitably be greater than that of a single bulk order contract regardless of how the market demand changes in the future. The retailer abandons the bulk order quantity $Q$ and uses the option order quantity $M^{*}$ for all of its order quantities. Similarly, when the price parameters meet $\left(c_{o}\left(\mu_{s}-v_{r}\right) /\left(\mu_{s}+I-c_{e}\right)\right)+v_{r}>w$, the retailer's cost of a mixed order strategy will inevitably be greater than that of a single bulk order contract regardless of how the market demand changes in the future. The retailer abandon the bulk order quantity $Q$ and use the option order quantity $M^{*}$ for all of its order quantities. In other cases, the retailer can adopt the mixed order strategy for revenues maximization.

Because $F(x)$ and $F^{-1}(x)$ have the same function increase and decrease. We have easily established that $\partial F\left(Q^{*}\right) / \partial v_{r}<0$ and $\partial F\left(Q^{*}+M^{*}\right) / \partial \mu_{s}>0$. The following discussion deals with the correlation between 
$Q^{*}, M^{*}$ and $c_{e}$.

Theorem 2 For joint purchase model integrating the bulk order contract, the option contract and the spot market, the execution price $c_{e}$ decrease with total order quantity $Q^{*}+M^{*}$, increase with bulk order quantity $Q^{*}$ and decrease with option order quantity $M^{*}$.

Proof. See Appendix B.

Theorem 2 show that If the supplier increase the option execution price $c_{e}$ to boost the retailer's bulk order contract quantity $Q^{*}$ and reduce the order quantity of option contract $M^{*}$, it also reduces the total order quantity of retailer $Q^{*}+M^{*}$. Increasing the option price by the supplier means that it is a higher chance the spot market price in the future is less than the option price, and this result will inevitably enable the retailer to take the spot market as a replenishment channel in the future. The reduction in the total order quantity also means reduced profits of the supplier. Therefore, only the supplier sets up a rational option execution price could it reach a win-win situation between the supplier and the retailer. Furthermore, from Eq. (7) and Eq.(8) it is not possible to analyze the impacts on the bulk order contract $Q^{*}$ and the reduction order quantity of option contract $M^{*}$ imposed by the spot price fluctuation $\sigma_{s}$ directly. This issue is to be analyzed by numerical simulation.

\section{Simulation and Analysis}

\subsection{Instance Verification}

This section provides further analysis of the study issue by virtue of examples and simulations. In the process of bulk goods trading, such as metals and agricultural products, excluding the speculative factors, enterprises take the spot market and the futures market as the channels for replenishment. According to the historical data of transactions in the spot market and commodity market demand data obtained, reasonable market forecasts are made to determine the optimal purchase quantity of bulk order contract and order quantity of option contract for revenues maximization. This section takes the sales of cotton by a textile company as an example. The spot price of the "Cotton Futures 1509 (CF 1509)" (data from Hexun Futures Network) is taken as the historical data. From Sep. 16, 2014 to Nov. 30, 2015, there is a total of 294 pieces of transaction data regarding the spot price of " $\mathrm{CF}$ 1509". The company defines that the market demand in the future meets the normal distribution $N_{D} \sim\left(200,30^{2}\right)$ tons in the future based on its own sales data. From Dec. 1, 2015 to Nov. 9, 2016, the delivery price of "CF 1609" $c_{s}=\mathrm{RMB} 11,660 /$ ton; and the reference cotton price in the spot market on that day is RMB 12,967 /ton. The annual risk-free rate of banks in 2015 is $1.85 \%$ (China's three-month bank deposit rate in 2015). The closing price of cotton futures trading on the first day of each week in 2015 is sampled, from which the approximate annual price fluctuation rate of "CF 1509" of $22.6 \%$ is obtained. Based on the Black-Scholes Model, the call price per unit of commodity $c_{o}=1860$ and the put price per unit of commodity $c_{o}=392$. Assuming that the wholesale price per unit of commodity based on bulk order contract wholesale price $w=\operatorname{RMB} 11,000$ 
/ton, the commodity residual value $v_{r}=8000$.

Calculated by Matlab Simulation, the company may maximize revenues when it buys the put option at the option price $c_{o}=392$, obtaining the order quantity of the bulk contract $Q^{*}$ and the order quantity of option contract $M^{*}$. The call option developed based on the option price $c_{o}=1860$ does not meet the condition given in Theorem 1, where the company should not purchase options and cannot maximize revenues. The textile company should buy the put option which tends to lower the purchase risk. If the condition of Theorem 1 is met, the order quantity of the bulk contract $Q^{*}$ and the order quantity of option contract $M^{*}$ can be obtained by the Eq. (7) and Eq.(8). Upon expiry of the futures, the commodity futures price is very close to the spot price. Table 1 gives the decisions of order quantities for purchase on Dec. 1, 2015 and delivery in Sep. 2016 under different means and standard deviations; the company obtained it while forecasting the spot price trend in the future based on the historic records of commodity trading prices in the futures market.

Table 1 Strategic values of order quantity under different means and standard deviations

\begin{tabular}{llllll}
\hline Time & Items & $\begin{array}{l}\text { Means, standard } \\
\text { deviations }\end{array}$ & $\begin{array}{l}\text { Total order } \\
\text { (ton) }\end{array}$ & $\begin{array}{l}\text { Bulk order } \\
\text { (ton) }\end{array}$ & $\begin{array}{l}\text { Option order } \\
\text { (ton) }\end{array}$ \\
\hline 3months & 49 & 13596,414 & 225.00 & 159.80 & 65.20 \\
6 months & 105 & 13507,332 & 223.98 & 159.80 & 64.18 \\
9 months & 150 & 13433,325 & 223.08 & 159.79 & 63.29 \\
12 months & 235 & 13168,499 & 219.40 & 159.73 & 59.67 \\
14 months & 294 & 12940,660 & 215.46 & 159.63 & 55.83 \\
\hline
\end{tabular}

The simulation results in Table 1 show that in the past 14 months, the trading price in the spot market was declining and the commodity price given in the futures market was also declining. With the decrease of the average forecasting price of the commodity spot price, the total order quantity by the company shows a downward trend. Within the given range of the change rate of market price, the bulk order quantity by the company calculated based on the model is basically not affected by the mean and standard deviation and accounts for a large proportion of the total order quantity. At the same time, both the option contract and the spot market become the effective replenishment channels for the company. Based on the given data base, the company purchased less commodity options when Theorem 1 was met. It indicates that the low price trend that may appear in the spot market in the future raised the possibility that company replenishes from the spot market so as to reduce the investment risk of options purchase and lower purchase costs. This conclusion is consistent with the theoretical results derived by the joint purchase model. Next it is to further analyze the impacts on the order quantity of bulk order contract and the order quantity of option contract imposed by the spot price fluctuation and the changes.

\subsection{Simulation Analysis and Discussion}

The analysis of the actual data above shows the feasibility of the model. However, it fails to reflect the impacts on the replenishment quantities from varied channels imposed by the purchase price fluctuation in the market in the future made by the retailer based on the market price information it has obtained. Now it is to analyze the impacts on the order quantity of bulk order contract and the order quantity of option contract imposed by the spot price fluctuation by means of numerical simulation. Assume a normal distribution of market demand

$N_{D} \sim\left(200,30^{2}\right)$, a normal distribution of the unit spot price of commodity $N_{C_{s}} \sim\left(12,5^{2}\right)$, the unit option price 
of commodity $c_{o}=1.2$, the unit option execution price of commodity $c_{e}=10$, the unit wholesale price of bulk order contract $w=7$, and the commodity residual value $v_{r}=0$. From the numerical assumption we can see that under the given conditions, the spot price is close to the option execution price, where the spot price may be either greater or less than the option execution price. However, the spot price is generally greater than the option execution price. The assumption allows for the retailer to perform the option contract, which is in line with the actual situation of joint purchase.

(1) Impacts on the order quantity of bulk order contract and the order quantity of option contract imposed by the spot price fluctuation and the changes

It is to analyze the impacts on the order quantity of bulk order contract $Q^{*}$ and the order quantity of option contract $M^{*}$ imposed by the spot price fluctuation parameter $\sigma_{s}^{2}$. As shown in Figs. 1 and 2, under the condition of the given expected spot market price $\mu_{s}$, the order quantity of bulk order contract decreases as the spot price variance increases and the order quantity of option contract increases as the spot price variance increases. It indicates that when the commodity price fluctuation increases in the spot market, retailers are more willing to order in the form of option contract due to the risk caused by the fluctuation. At the same time, for the purpose of lowering purchase risk, the retailer will also reduce the order quantity of bulk order contract $Q^{*}$ and increase the order quantity of option contract $M^{*}$. This situation complies with the transfer of purchase risk by the retailer to the supplier, e.g. the issuer of option contract, by using the option contract as a form of joint purchase. In addition, this kind of joint purchase strategy is also capable of meeting market demands in the future to the greatest extent and maximizes revenues.

As shown in Fig. 2, under the given spot price expectation $\mu_{s}$ and the variance $\sigma_{s}^{2}$, there is a chance that $\sigma_{s}^{2}$ renders $M^{*} \leqslant 0$. By substituting the simulation data into Theorem 1 , when the retailer's forecasting spot price expectation $\quad \mu_{s}=12 \quad, \quad M^{*}<0 \quad$ when $\quad \sigma_{s}<1.5 \quad$. If the condition $c_{e}-\mu_{s}+\frac{c_{o}\left(\mu_{s}-v_{r}\right)}{w-v_{r}}<\int_{0}^{c_{c}}\left(c_{e}-s\right) \operatorname{sg}(s) d s<c_{e}-v_{r}$ is not met, the retailer should not order from option contract but solely from bulk order contract. When the forecasting spot price expectation and variance meet the condition of Theorem 1, the retailer may implement the order quantity of option contract $M^{*}$. The more sufficient of the historic data of commodity purchase in the spot market the retailer has obtained, the more accurate spot market price it can forecast, and the more accurate joint purchase strategy it can make. Through the data simulation, Fig. 3 shows that with increase of the spot market price fluctuation, the retailer has both the futures market orders and the total orders increased. It suggests that the option contract can play an indeed effective way in avoiding purchase risks for retailers. 


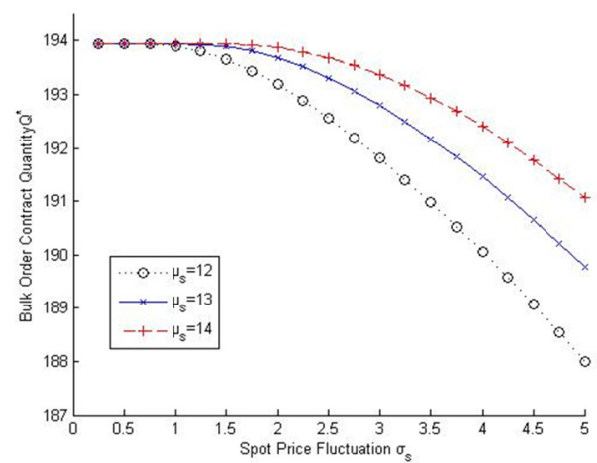

Figure 1. Effect of $\sigma_{s}$ on $Q^{*}$

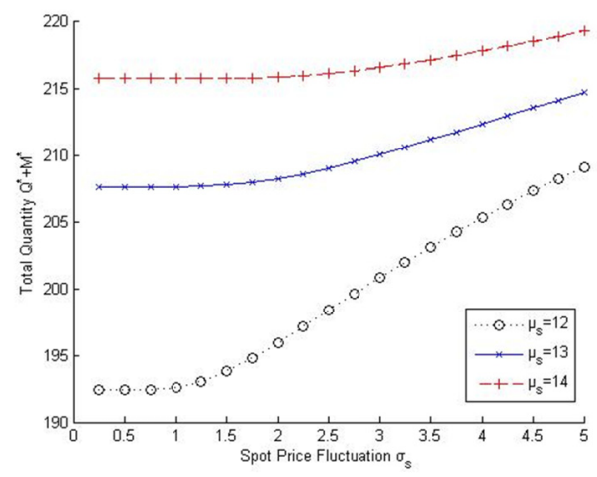

Figure 3. Effect of $\sigma_{s}$ on $Q^{*}+M^{*}$

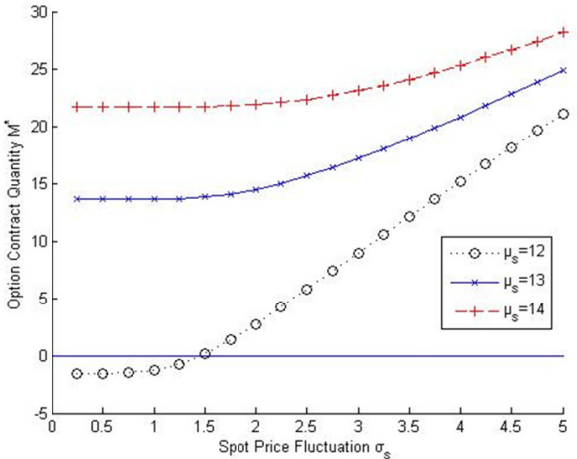

Figure 2. Effect $\sigma_{s}$ on $M^{*}$

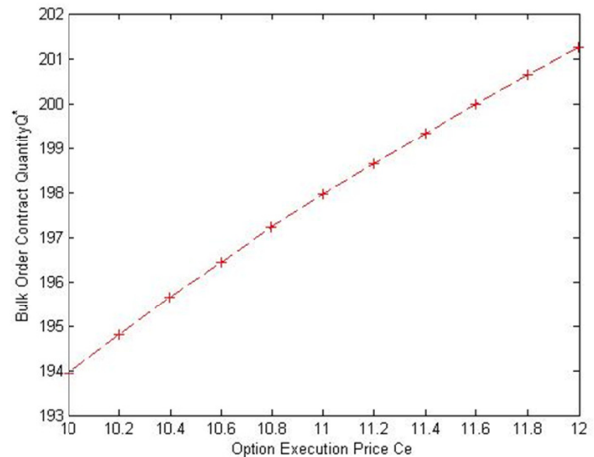

Figure 4. Effect of $c_{e}$ on $Q^{*}$

(2) Impacts on the order quantity of bulk order contract and the order quantity of option contract imposed by varied option execution prices and the changes

Through the numerical simulation, the impacts on the order quantity of bulk order contract $Q^{*}$ and the order quantity of option contract $M^{*}$ imposed by varied option execution price are analyzed (as shown in Fig.4). It shows that the order quantity of bulk order contract increases as the option execution price increases. As shown in Fig. 5, the order quantity of option contract decreases as the option execution price increases. In practice, it means that as the option execution price increases, the retailer's order costs to be paid to the supplier increases compared to bulk order contract with a fixed wholesale price. As a result, the retailer will choose to increase the order quantity of bath order contract to minimize order costs. The increase in the option execution price also implies a higher chance that the spot price in the sales season is less than the option execution price. Therefore the retailer orders more from bulk order contract and less from option contract. The difference between the market demand in the future and the total order quantity will be replenished from the spot market. Fig. 6 shows that the retailer's total order amount $Q^{*}+M^{*}$ decreases as the option execution price increases.

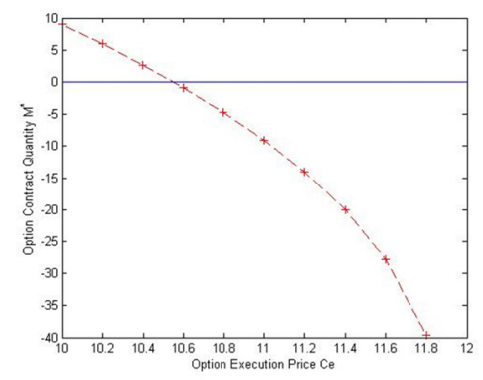

Figure 5. Effect of $c_{e}$ on $M^{*}$

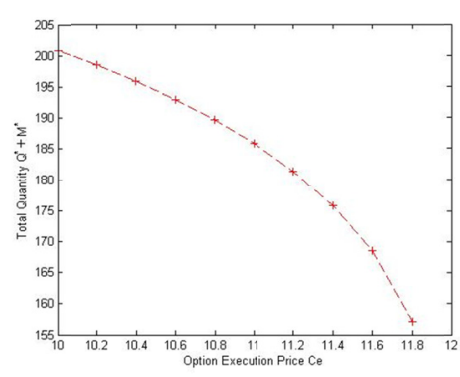

Figure 6. Effect of $c_{e}$ on $Q^{*}+M^{*}$ 


\section{Conclusion}

This paper focuses on the joint purchase and order strategy integrating the bulk order contract, the option contract and the spot market for retailers. By establishing a joint purchase model and solving the model for analysis, the order conditions and strategies for implementing joint purchase are obtained; an example in terms of retailer's joint purchase is given; and the impacts on the optimal purchase quantity of the retailer imposed by the key factors such as the market price fluctuation and the option execution price are analyzed by means of numerical simulation. Conclusions are as follows:

(1) The involvement of the spot market brings about more purchase channels for retailers and expands the purchase method based on option contract. However, it also increases the uncertainty of option contract purchase.

When the option price $\left(c_{o}, c_{e}\right)$ issued by the supplier and the purchase price distribution in the spot market $\left(\mu_{s}, \sigma_{s}^{2}\right)$ forecasted by the retailer meet the condition of Theorem 1 , the retailer may maximize its revenues by adopting a joint purchase strategy integrating the bulk order contract, the option contract and the spot market.

(2) When the spot market is involved, the total order quantity $Q^{*}+M^{*}$ comprising bulk order contract and option contract is negatively correlated with the option execution price $c_{e}$ and is positively correlated with the spot price fluctuation $\sigma_{s}$; the order quantity of bulk order contract $Q^{*}$ is positively correlated with the option execution price $c_{e}$ and is negatively correlated with the spot price fluctuation $\sigma_{s}$; and the order quantity of option contract $M^{*}$ is negatively correlated with the option execution price $c_{e}$ and is positively correlated with the spot price fluctuation $\sigma_{s}$.

In the paper, it is of some practical significance for developing reasonable joint purchase strategies to take the bulk order contract as the main purchase channel and the option contract and the spot market as replenishment channels for retailers. Further study interests will focus on combined purchase strategies and the mechanism of supply chain coordination under the conditions related to the commodity price in the spot market and the market demand.

\section{Acknowledgments}

The authors thank the editor, associate editor, and two reviewers for their constructive comments, which have improved this article tremendously. This work is partly supported by the National Natural Science Foundation of China (NSFC, project no.:71572033, 71172174)

\section{References}

Arani, H. V., Rabbani, M., \& Rafiei, H. (2016). A revenue-sharing option contract toward coordination of supply chains. International Journal of Production Economics, 178, 42-56. https://doi.org/10.1016/j.ijpe.2016.05.001

Barnes-Schuster, D., Bassok, Y., \& Anupindi, R. (2002). Coordination and flexibility in supply contracts with options. Manufacturing \& Service Operations Management, 4(3), 171-207. https://dx.doi.org/10.1287/msom.4.3.171.7754

Black, F., \& Scholes, M. (1973). The pricing of options and corporate liabilities. The Journal of Political Economy, 637-654. https://doi.org/10.1086/260062

Fu, Q., Lee, C. Y., \& Teo, C. P. (2010). Procurement management using option contracts: random spot price and the portfolio effect. IIE transactions, 42(11), 793-811. http://dx.doi.org/10.1080/07408171003670983

Hong, Z., \& Lee, C. (2013). A decision support system for procurement risk management in the presence of spot 
market. Decision Support Systems, 55(1), 67-78. https://doi.org/10.1016/j.dss.2012.12.031

Inderfurth, K., \& Kelle, P. (2011). Capacity reservation under spot market price uncertainty. International Journal of Production Economics, 133(1), 272-279. https://doi.org/10.1016/j.ijpe.2010.04.022

Liu, C., Jiang, Z., Liu, L., \& Geng, N. (2013). Solutions for flexible container leasing contracts with options under capacity and order constraints. International Journal of Production Economics, 141(1), 403-413. https://doi.org/10.1016/j.ijpe.2012.09.005

Martínez-de-Albéniz, V., \& Simchi-Levi, D. (2005). A portfolio approach to procurement contracts. Production and Operations Management, 14(1), 90-114. https://doi.org/10.1111/j.1937-5956.2005.tb00012.x

Merzifonluoglu, Y. (2015). Risk averse supply portfolio selection with supply, demand and spot market volatility. Omega-International Journal of Management Science, 57, 40-53. https://doi.org/10.1016/j.omega.2015.03.006

Seifert, R. W., Thonemann, U. W., Hausman, W. H. (2004). Optimal procurement strategies for online spot markets. European Journal of Operational Research, 152(3), 781-799.

Xing, W., Wang, S., \& Liu, L. (2012). Optimal ordering and pricing strategies in the presence of a B2B spot market. European Journal of Operational Research, 221(1), 87-98.

Zhao, Y., Ma, L., Xie, G., \& Cheng, T. E. (2013). Coordination of supply chains with bidirectional option contracts. European Journal of Operational Research, 229(2), 375-381.

\section{Appendix A. The Proof of Theorem 1.}

Using the Leibniz rule in Eq. (6),

$$
\begin{aligned}
& \frac{\partial E_{C_{s}}\left(E\left(\Pi_{R}\right)\right)}{\partial Q}=-w+\mu_{s}+\left(v_{r}-A-c_{e} B\right) F(Q)-\left(\mu_{s}-A-c_{e} B\right) F(Q+M) \\
& \frac{\partial E_{C_{s}}\left(E\left(\Pi_{R}\right)\right)}{\partial M}=-c_{o}+\left(\mu_{s}-A-c_{e} B\right)[1-F(Q+M)] \\
& \frac{\partial^{2} E_{C_{s}}\left(E\left(\Pi_{R}\right)\right)}{\partial Q^{2}}=\left(v_{r}-A-c_{e} B\right) f(Q)-\left(\mu_{s}-A-c_{e} B\right) f(Q+M) \\
& \frac{\partial^{2} E_{C_{s}}\left(E\left(\Pi_{R}\right)\right)}{\partial M^{2}}=\frac{\partial^{2} E_{C_{s}}\left(E\left(\Pi_{R}\right)\right)}{\partial Q \partial M}=\frac{\partial^{2} E_{C_{s}}\left(E\left(\Pi_{R}\right)\right)}{\partial M \partial Q}=-\left(\mu_{s}-A-c_{e} B\right) f(Q+M)
\end{aligned}
$$

The Hessian of $E_{C_{s}}\left(E\left(\Pi_{R}\right)\right)$ can be written as follows:

$$
H=-\left(v_{r}-A-c_{e} B\right)\left(\mu_{s}-A-c_{e} B\right) f(Q) f(Q+M)
$$

Let $X=A+c_{e} B=c_{e}-I, \mathrm{H}$ can be rewritten as follows:

$$
H=-\left(v_{r}-X\right)\left(\mu_{s}-X\right) f(Q) f(Q+M)
$$

If the condition for $v_{r}<X<\mu_{s}$ is met, the Hessian of $E_{C_{s}}\left(E\left(\Pi_{R}\right)\right)$ is negative definite and $E_{C_{s}}\left(E\left(\Pi_{R}\right)\right)$ is concave, making first-order conditions sufficient: 
$\partial E(\Pi(Q, M)) / \partial Q=0, \quad \partial E(\Pi(Q, M)) / \partial M=0$.

Solving jointly purchase quantity in the bulk order contract $Q$ as eq.(7) and in the option contract $\mathrm{M}$ as eq.(8).

To make $M^{*}$ exist, the condition $F\left(Q^{*}+M^{*}\right)-F\left(Q^{*}\right)>0$ is set. Using eq.(8) minus eq.(7), the boundary condition is found as follows:

$I>c_{e}-\mu_{s}+\frac{c_{o}\left(\mu_{s}-v_{r}\right)}{w-v_{r}}$

Thus, if the condition for $c_{e}-\mu_{s}+\frac{c_{o}\left(\mu_{s}-v_{r}\right)}{w-v_{r}}<I<c_{e}-v_{r}$ is met, then the unique optimal $Q^{*}$ and $M^{*}$ is determined respectively by eq.(7) and eq.(8). $\square$

Appendix B. The Proof of Theorem 2.

Because $F(x)$ and $F^{-1}(x)$ have the same function increase and decrease. The first-order derivatives of $F\left(Q^{*}\right)$ and $F\left(Q^{*}+M^{*}\right)$ are as follows:

$\frac{\partial F\left(Q^{*}\right)}{\partial c_{e}}=\frac{\left(1-G\left(c_{e}\right)\right)\left(w-v_{r}-c_{o}\right)}{\left(v_{r}-c_{e}-A\right)^{2}}>0$

$\frac{\partial F\left(Q^{*}+M^{*}\right)}{\partial c_{e}}=\frac{-\left(1-G\left(c_{e}\right)\right) c_{o}}{\left(\mu_{s}-c_{e}-A\right)^{2}}<0$

For $F\left(Q^{*}+M^{*}\right)>F\left(Q^{*}\right), F\left(Q^{*}\right)$ is convex in $c_{e}$, and $F\left(Q^{*}+M^{*}\right)$ is concave in $c_{e}$. Thus, $M^{*}$ is decreasing in $c_{e}$.

\section{Copyrights}

Copyright for this article is retained by the author(s), with first publication rights granted to the journal.

This is an open-access article distributed under the terms and conditions of the Creative Commons Attribution license (http://creativecommons.org/licenses/by/4.0/). 